\title{
Nutritional implications in chronic liver diseases
}

\begin{abstract}
Chronic liver disease presents with great nutritional impact, since the liver is the organ responsible for several biochemical pathways related to the production, modification and use of nutrients, among other important metabolic substances. Changes in anthropometric, biochemical and clinical indicators, associated with inadequate food intake are common in chronic liver disease. Changes in water compartments-ascites and peripheral edema-related to hypoalbuminemia and malnutrition are also present in the decompensated disease. The provision of specific nutritional therapy (oral, enteral and/or parenteral) is capable of promoting improvements in some parameters of the liver function. It also helps the nutritional status of the chronic liver disease in its various stages, contributes to the improvement of the quality of life and reduces the rate of complications, as well as morbidity and mortality.
\end{abstract}

Keywords: chronic liver disease, nutrition, nutritional status, hepatic encephalopathy, alcoholism
Volume 3 Issue 5 - 2017

\author{
Renata Costa Fortes \\ Nutrition course, Universidade Paulista, Brazil
}

Correspondence: Renata Costa Fortes, Nutrition course, Institute of Health Sciences, Universidade Paulista (UNIP)Brasília (DF), Brazil, Email fortes.rc@gmail.com

Received: September 0I, 2017 | Published: November 20, 2017
Abbreviations: SGA, subjective global assessment; MI, maastricht index; NRI, nutritional risk index; BMI, body mass index; ESPEN, european society for parenteral and enteral nutrition; NT, nutritional therapy; BCAA, branched-chain amino acids; AAA, aromatic amino acids; MNTT, multiprofessional nutritional therapy team

\section{Mini review}

Chronic liver disease-an inflammatory reaction in the liver of variable etiology and severity, with a progressive evolution characterized by the presence of fibrosis and alteration of the normal hepatic structure-presents with great nutritional impact, since the liver is the organ responsible for several biochemical pathways related to the production, modification and use of nutrients, among other important metabolic substances.

Early stage liver disease may be asymptomatic or with nonspecific symptoms such as fatigue, anorexia/hyporexia, fever and malaise, easily confused with other diseases. As the disease progresses, hepatic insufficiency and portal hypertension may present with a symptomatic picture characterized by ascites, gastric/esophageal veins hemorrhage and hepatic encephalopathy. ${ }^{2}$

Chronic liver failure represents a continuous aggression to the hepatic parenchyma and has a multifactorial etiology, such as alcoholism, viral infections and accumulation of cytoplasmic fat and/or autoimmune disease. ${ }^{3}$ When the disease is irreversible and symptomatic, the prospect of survival is less than one year and, in these cases, liver transplantation may be indicated, since there are no clinical and/or surgical therapeutic alternatives. ${ }^{4}$

The high mortality rate is present in chronic liver failure in detriment of the reduced functional capacity of the liver that can exceed $80 \%$, a condition characterized by liver failure. In addition, this insufficiency is associated with an increased risk of developing hepatic encephalopathy. ${ }^{3}$

Hepatic encephalopathy, a neuropsychiatric syndrome characterized by changes in personality, behavior, reduction of cognition, motor function and level of consciousness is potentially reversible. However, during this clinical situation, an unfavorable prognosis with a high mortality rate is observed. ${ }^{2,3}$

Changes in anthropometric, biochemical and clinical indicators, associated with inadequate food intake are common in chronic liver disease. Changes in water compartments-ascites and peripheral edema-related to hypoalbuminemia and malnutrition are also present in the decompensated disease. ${ }^{1,3}$ Other changes present in chronic liver diseases include those related to the Intermediary metabolism of carbohydrates, lipids, proteins, vitamins and minerals that oscillate according to the degree of impairment of liver function, which negatively influences the nutritional status of these patients. ${ }^{1,3,5}$

Studies indicate that malnutrition is present in $20 \%$ to $80 \%$ of the patients with liver disease depending on the clinical stage of the disease. There is a high prevalence of malnutrition, especially in those with decompensated cirrhosis. Already, in patients on a liver transplant list, malnutrition may reach $100 \%$ of the cases. ${ }^{3,6}$

Malnutrition is an independent risk factor for mortality of patients with chronic liver disease. It has a negative impact on the patient's prognosis, increasing hospitalization time, the incidence of infections and their complications, as well as contributing to the appearance of ascites, hepatic encephalopathy, urinary, pulmonary and spontaneous bacterial peritonitis. ${ }^{7-9}$

In addition to malnutrition, involuntary weight loss and intense depletion of lean cell mass can occur at all stages of the disease, leading to worse clinical outcomes. Thus, sarcopenia, presence of both low skeletal muscle mass and low skeletal muscle function, is emphasized in patients with chronic liver disease capable of negatively influencing quality of life, physical performance, morbidity, transplantation success and even mortality. ${ }^{10-13}$

Increased resting energy expenditure associated with insufficient dietary intake may also contribute to the malnutrition process, mainly due to the installation of negative energy balance, with consequent increase in susceptibility to infectious complications and morbidity and mortality. ${ }^{3}$ Nutritional assessment is essential to the investigation of changes associated with liver diseases, since it supports the correction and/or maintenance of nutritional status. ${ }^{14}$ However, there is no gold standard method for nutritional evaluation of patients with chronic liver disease. ${ }^{3,15,16}$ 
Studies show that multi compartmental bioimpedance is capable of significantly increase the prevalence of malnutrition diagnosis when compared to subjective methods (Subjective Global AssessmentSGA) and objectives (anthropometry and biochemical tests) of nutritional status assessment. ${ }^{3,15,16}$ The use of the Maastricht index (MI) and the nutritional risk index (NRI) in the evaluation of liver disease patients are also suggested, in order to increase the sensitivity and specificity of nutritional diagnosis. ${ }^{3}$

Among the anthropometric measures most commonly used in liver diseases, the following stand out: weight, height, body mass index (BMI), skin folds (triceps and brachial), arm circumference, arm muscle circumference and arm muscle area. The muscular strength measured by dynamometry and the thickness of the adductor muscle of the thumb can also complements the nutritional evaluation. For biochemical methods, pre-albumin, albumin, transferrin, lymphocyte count and total blood count are priority. ${ }^{17}$

The most recent European Society for Clinical Nutrition and Metabolism (ESPEN) guidelines recommend applying the SGA and anthropomorphic measures (triceps skin-fold thickness, midarm circumference) to identify patients at risk for malnutrition and to quantify malnutrition with bioelectrical impedance analysis. ${ }^{18}$

After the nutritional diagnosis is established, nutritional therapy (NT) is indicated to help improving the quality of life and the liver function, decreasing the rate of complications and reducing mortality. Other goals of NT include: maintaining and/or regaining adequate body weight; the control of both muscular and visceral protein catabolism; maintain positive nitrogen balance, acute phase protein synthesis and hepatic regeneration, without increasing the risk of hepatic encephalopathy. ${ }^{3} \mathrm{~A}$ chronic imbalance of amino acids is observed in chronic liver disease; that is, reduction of branchedchain amino acids (BCAA) and increase of aromatic amino acids (AAA), leading to cerebral limitation of BCAAs, which contributes to the development of hepatic encephalopathy. The use of specialized formulas supplemented with AACR to reduce mortality in patients with hepatic encephalopathy is inconclusive. The use of AACR is indicated only for patients who are on hepatic encephalopathy already using enteral nutritional therapy with standard formulations. Enteral nutritional therapy also reduces the risk of complications such as hepatic encephalopathy, infections and also the risk of postoperative mortality. The oligomeric formula is indicated only when there is intolerance to the polymer formulas. Formulas with a caloric density higher than one calorie per $\mathrm{mL}$ of $\operatorname{diet}(\mathrm{Cd} \geq 1 \mathrm{kcal} / \mathrm{mL})$ containing all essential amino acids with a sodium content $\leq 40 \mathrm{mEq} /$ day should be prioritized. ${ }^{3}$ In the presence of active esophageal varices or with a risk of significant bleeding, it is contraindicated the passage of a catheter; however, it is essential the performance of the multi professional nutritional therapy team (MNTT) to discuss each case. To prevent or control hepatic encephalopathy, especially in the lower grades of the Wast-Haven Scale, protein restriction is contraindicated, since this restriction does not appear to have any beneficial effect for cirrhotic patients during hepatic encephalopathy. ${ }^{3}$

Studies indicate that patients with cirrhosis and hepatic encephalopathy may benefit themselves from the use of modified normocaloric $(30 \mathrm{kcal} / \mathrm{kg}$ of body weight/day) or hyperproteic $(1.2 \mathrm{~g}$ protein $/ \mathrm{kg}$ of body weight/day) diets, with increased vegetable and dairy proteins intake; and with significant reduction of plasma ammonia. ${ }^{3,19,20}$ The recommendations of ESPEN ${ }^{18}$ and ASPEN $^{21}$ are described in Table 1. Other foods such as prebiotics, probiotics and symbiotics are indicated in the prevention and treatment of hepatic encephalopathy, being the use of symbiotics the one with more consistent results. ${ }^{3}$ Specific deficiencies in proteins, polyunsaturated fatty acids and micronutrients (vitamins $\mathrm{C}, \mathrm{D}$ and $\mathrm{E}$, carotenoids and selenium) were linked to sarcopenia, which can affect up to $70 \%$ of patients with advanced liver disease. ${ }^{11,22}$ The combination of diet modification and nutrient supplementation with an organized exercise program can help improve or even reverse the effects of sarcopenia in an already complex disease process. ${ }^{11}$

Table I Energy and Protein Recommendations in Chronic Liver Disease

\begin{tabular}{llll}
\hline \multicolumn{2}{l}{ Recommendations } & & \\
\hline Guidelines & Energy & Protein & Situation \\
\hline ESPEN & $35-40 \mathrm{kcal} / \mathrm{kg} / \mathrm{day}$ & $1.0-1.5 \mathrm{~g} / \mathrm{kg} /$ day & \\
ASPEN & $35 \mathrm{kcal} / \mathrm{kg} /$ day & $0.6-0.8 \mathrm{~g} / \mathrm{kg} /$ day & $\begin{array}{l}\text { With acute } \\
\text { encephalopathy } \\
\text { Without } \\
\text { encephalopathy } \\
\end{array}$ \\
& $25-35 \mathrm{kcal} / \mathrm{kg} /$ day & $1.0-1.5 \mathrm{~g} / \mathrm{kg} /$ day & $\begin{array}{l}\text { Stable and } \\
\text { malnourished }\end{array}$ \\
\hline i. ESPEN. ${ }^{18}$ & $30-40 \mathrm{kcal} / \mathrm{kg} /$ day & & \\
ii. ASPEN. ${ }^{21}$ & & & \\
\hline
\end{tabular}

\section{Conclusion}

Inflammation and fatty infiltration in the liver can be reduced by the use of $1 \mathrm{~g} /$ day of omega- 3 fatty acid, as well as a decrease in plasma triglyceride levels, TNF- $\alpha$ levels, liver enzymes, fasting glycemia and hepatic steatosis levels with the daily supplementation of $2 \mathrm{~g}$ of omega- 3 . $^{3}$ Therefore, the provision of specific nutritional therapy (oral, enteral and/or parenteral) is capable of promoting improvements in some parameters of the liver function. It also helps the nutritional status of the chronic liver disease in its various stages, contributes to the improvement of the quality of life and reduces the rate of complications, as well as morbidity and mortality.

\section{Acknowledgments}

None.

\section{Conflicts of interest}

The author declares that there is no conflict of interest.

\section{References}

1. Maio R, Dichi JB, Burini RC. Consequências nutricionais das alterações metabólicas dos macronutrientes na doença hepática crônica. Arq Gastroenterol. 2000;37(1):52-57.

2. D'Amico G, Garcia-Tsao G, Pagliaro L. Natural history and prognostic indicators of survival in cirrhosis: a systematic review of 118 studies. $J$ Hepatol. 2006;44(1):217-231.

3. Sociedade Brasileira de Nutrição Parenteral e Enteral Colégio Brasileiro de Cirurgiões Associação Brasileira de Nutrologia. Terapia Nutricional nas Doenças Hepáticas. Projeto Diretrizes. 2011;1-19.

4. Brandão ABM, Fleck Jr AM, Marroni CA. Indicações e Contraindicações de Transplante Hepático. In: Mattos AA, Dantas-Correa EB, editors. Tratado de Hepatologia. Rubio, Brazil: Rio de Janeiro; 2010. p. 877-889.

5. Miwa Y, Shiraki M, Kato M, et al. Improvement of fuel metabolism by nocturnal energy supplementation in patients with liver cirrhosis. Hepatol Res. 2000;18(3):184-189. 
6. Roongpisuthipong C, Sobhonslidsuk A, Nantiruj $\mathrm{K}$, et al Nutritional assessment in various stages of liver cirrhosis. Nutrition. 2001;17(9):761-765.

7. Lamoussenerie A, Picinbono-Larose C, Tremblay M, et al. Nutritional status assessment in patients with chronic liver disease: a pilot study. Journal Clinical and Experimental Hepatology. 2017;7(1):S64-S65.

8. Carvalho L, Parise ER. Evaluation of nutritional status of nonhospitalized patients with liver cirrhosis. Arq Gastroenterol. 2006;43(4):269-274.

9. Bémeur C, Butterworth RF. Nutrition in the management of cirrhosis and itsneurological complications. J Clin Exp Hepatol. 2014;4(2):141-150.

10. Pimentel CFMG, Lai M. Nutrition interventions for chronic liver diseases and nonalcoholic fatty liver disease. Med Clin North Am. 2016;100(1):1303-1370.

11. Kappus MR, Mendoza MS, Nguyen D, et al. Sarcopenia in patients with chronic liver disease: can it be altered by diet and exercise? Curr Gastroenterol Rep. 2016;18(8):43.

12. Meeks AC, Madill J. Sarcopenia in liver transplantation: A review. Clinical Nutrition. 2017;22:76-80.

13. Petta S, Ciminnisi S, Di Marco V, et al. Sarcopenia is associated with severe liver fibrosis in patients with non-alcoholic fatty liver disease. Aliment Pharmacol Ther. 2017;45(4):510-518.

14. Gunsar F, Raimondo ML, Jones S, et al. Nutritional status and prognosis in cirrhotic patients. Aliment Pharmacol Ther. 2006;24(4):563-572.
15. Ritter L, Gazzola J. Avaliação nutricional no paciente cirrótico: uma abordagem objetiva, subjetiva ou multicompartimental? Arq Gastroenterol. 2006;43(1):66-70.

16. Duarte ACG. Avaliação Nutricional: aspectos clínicos e laboratoriais. São Paulo, Atheneu, Brazil; 2007. p. 269-273.

17. Figueiredo FA, Perez RM, Freitas MM, et al. Comparison of three methods of nutritional assessment in liver cirrhosis: subjective global assessment, traditional nutritional parameters, and body composition analysis. J Gastroenterol. 2006;41:476-482.

18. Lalama MA, Saloum Y. Nutrition, Fluid, and Electrolytes in Chronic Liver Disease. Clinical Liver Disease. 2016;7(1):18-20.

19. Gheorghe L, Iacob R, Vadan R, et al. Improvement of hepatic encephalopathy using a modified high-calorie high-protein diet. Rom $J$ Gastroenterol. 2005;14(3):231-238.

20. Cordoba J, Lopez-Hellin J, Planas M, et al. Normal protein diet for episodic hepatic encephalopathy: results of a randomized study. $J$ Hepatol. 2004;41(1):38-43.

21. Frazier TH, Wheeler BE, McClain CJ, et al. Liver disease. In: Mueller CM, editor. The A.S.P.E.N. adult nutrition support core curriculum. USA: Silver Spring, American Society for Parenteral and Enteral Nutrition; 2012. p. 454-471.

22. Ponziani FR, Gasbarrini A. Sarcopenia in patients with advanced liver disease. Curr Protein Pept Sci. 2018;19(7):681-691. 